\title{
A Web-based Multimedia Annotation System for Language Learning
}

\author{
Kuo-Yu Liu and Herng-Yow Chen \\ Providence University \& National Chi-Nan University \\ Taiwan, Republic of China
}

\section{Introduction}

In the early Web-based learning systems, the online teaching/learning resources are restricted in static hypertext or images which can be delivered efficiently over the Internet. With the emerging of the dynamic HTML and network streaming technologies, the online courses can be designed more vivid and vigorous by integrating animations and multimedia (e.g., audio/video) features. Thus, an alternative lecture presentation can be elaborately designed by tightly integration of streaming audio/video clips and HTML-based lecture slides with animated objects. According to research work of Lauer and Schar (Lauer et al., 2001; Schar \& Krueger, 2000), the voice and animation can have a structuring effect and engage the user's attention to important elements than the static text or pictures. For example, many Web lecture systems (Brusilovsky, 2000) attempt to integrate multimedia technologies for providing an easy way to capture or access lecturing content through the network. In this chapter, we keep the core ideas of automated capture and structural access of Web lectures in mind to develop a system, Web-based Multimedia Annotation system (WMA), for instructors to record the lecturing process or the correction process of students' compositions on language leaning courses.

The WMA system is aimed at capturing of teacher's lecture activities (e.g., voice and navigation events, such as tele-pointer, highlight, or pen strokes, imposed on HTML-based lecture slides) and replaying the scene faithfully by multimedia synchronization techniques (Steinmetz, 1996). The capturing and presentation processes are helpful for live experience lecture recording and efficient information access. For instance, the capturing techniques support the recording of as much relevant media streams as possible during the lecturing(e.g., voice/video or navigation events) and the presentation techniques support the flexibility in document interactions (e.g., random access and playing a specific speech segment repeatedly). Both of the techniques were implemented to support the lecturing recording or English composition correction in the WMA system.

In addition to capturing and replaying abilities on lectures, the WMA system provides the following features to assist instructors in composition correcting process and to assist students in re-editing the composition errors: (1) to ease the pressure on instructors who need to record the correcting process in real-time, an alternative mechanism is designed, which allows: (i) revising content directly like a text editor, (ii) comparing the differences of 
content between revisions automatically, and (iii) recording the voice comments with navigation events. (2) To compatible with the editing trace function of the popular MS Word, we designed several proofreading symbols which could further explore essential significance between pen strokes or text annotations, and underlying characters automatically after the instructor corrects a composition. The integration enables the system to translate the corrected points (i.e. proofreading symbols) to editing trace function provided in MS Word.

The remainder of this chapter is organized as follows. We address the related work in presentation recording and some of systems for helping comprehension of language learning in Section 2. An overview of WMA system, including the architecture and major characteristics, will be described in Section 3. Section 4 states the detailed descriptions about the recording procedures. The different presentation modes for recorded lecture will be described in Section 5. Finally, conclusion remarks will be given in Section 6 .

\section{Related Work}

In this section, we discuss some of related work in presentation recording and several systems for helping comprehension of writing. This discussion includes the previous work in the field of automated capture mechanisms and applications. These issues are important for establishing an integrated learning environment which can increase the user interaction and structural content accessibility. Furthermore, we also discuss several systems that could serve as applications for improving writing skill to reveal the usability of computers.

\subsection{Presentation Recording}

To fully utilize the benefits of computer and multimedia networking, much research has been devoted to capture the media streams occurring in live presentations for later access. We summarized these systems into the following types by the capturing approaches: (1) Camera-based recording, (2) Electronic whiteboard-based recording, and (3) Computer-based recording.

(1) Camera-based Recording: To tape a live lecture with video cameras and turn it into a streaming-media document is an intuitively approach when talking about the presentation recording (Cruz \& Hill, 1994). The advantage of this approach is that lecturers can fully concentrate on the contents without adapting to new technology. However, to provide acceptable quality of recorded lectures for increasing readability and accessibility should invest much manpower in operation of recording equipments and much time in postprocessing of recording content. The former problem can be solved by the automated camera management systems requiring little or no human intervention (Suganuma, 2002; Rui et al., 2004), and one solution for solving the latter problem is to survey the tools provided by computer vision and computer graphics that allow researchers to determine syntactic information about images (Gleicher et al., 2002; Wang et al., 2003). Another compromise solution is to integrate recorded video with lecturing slides. Several existing presentation systems (e.g., Microsoft Producer or Accordent's PresenterONE) and research projects (e.g., Cornell Lecture Browser (CLB) (Mukhopadhyay \& Smith, 1999), BMRC Lecture Browser (BIBS) (Rowe et al., 2001), and Asynchronous Learning Network (ALN) (Latchman \& Gillet, 2000)), allow recorded video to synchronize with original slides and enable users to have slide-based random access during the playback. The timestamp for 
each slide change event can be determined during the recording stage or automatic postprocessing. Although these systems make it possible to show the teaching materials more clearly for users, the instructional handwriting activities during the class are difficult to identify from the video and to present on the slides.

(2) Electronic Whiteboard-based Recording: The challenges of the presentation recording approaches described above are seem to the capturing of instructor's handwriting activities and the structural overview of recorded lectures. Several projects have been aimed at developing feasible tools integrating with high-tech equipments (e.g., SmartBoard) to capture as much as possible from the classroom experience (e.g., eClass (Brotherton, 2001), Smart Classroom (SC) (Shi et al., 2003), and tele-TASK (Schillings \& Meinel, 2002)). The touch-sensitive whiteboard allows pen input as well as the traditional blackboard and chalk instructional activities. Therefore, all data streams, such as video, audio, and annotations imposed on the slides will be captured for later playback. Further analysis of media relations for different access degrees, such as slide-based or handwriting-based random access, are provided for increasing content accessibility. However, this recording approach has two apparent disadvantages. One is the high cost for equipments and another is that everything remains purely static during the presentation. According to literatures (Schar \& Krueger, 2000) and (Lauer et al., 2001), dynamic presentation with animations is much better and helpful for descriptions of visualize dynamic phenomena or a process than static text or pictures.

(3) Computer-based Recording: Due to computers and network are in widespread use, many instructors are used to conduct a course by the assistance of computers. Through the advanced programming technologies, to capture a lecture which was taught on computers is no longer a hard work. The capturing can be classified into two mechanisms, one is screenbased recording and another is event-based recording.

- - Screen-based recording: The use of screen captures lead to a more effective and efficient manual for illustrating software functions or operations (Gellevij et al., 2002). Currently many commercial systems (e.g., Camtasia, Windows Media Encoder or PowerCam) not only provide screen capture to save as an image, but also provide functionalities to record any screen or window content together with instructor's audio and then produce a synchronized video output. Therefore, all events occurring on the screen will be captured as continuous images, including slide content, software operations, or handwritings. The scenario may benefit the lecturers who need to demonstrate computer programs or simulations; however, the document structure is difficult to generate because recording systems are difficult to detect the slide change event automatically.

-Event-based recording: This kind of systems usually contains a monitor to detect operations, including mouse and keyboard events, triggered by the lecturer over the application. A representative work by using this approach is the "Authoring on the Fly" system (Muller \& Ottmann, 2000). The idea of producing multimedia documents in this system is to combine the apparently distinct tasks of teaching in class and multimedia authoring into one single activity (Datta \& Ottmann, 2001). Instead of using real pen input equipments, two whiteboard applications, AOFwb and aofShell, which are actually computer input/output devices were implemented for lecturers to prepare materials and to capture live lecturing activities. All recorded streams, including the audio stream, the graphics stream, and the application stream, are synchronizable and randomly accessible. Additionally, the dynamics of the lecturer's handwritings on a slide are preserved during the playback of a lecture. The 
system attempted to realize ubiquitous computing vision for a lecture theater and make it more suitable for presentation recording from a live lecture; however, the complex user interface and preprocessing phase are tedious for lecturers. For ubiquitous computers, Web browser is a commonly used application for conveying information and knowledge over Internet in our daily life. The Web plug-in techniques (e.g., ActiveX, Java Applet, etc.) enable developers to enhance browsers' capabilities (e.g., voice recording) for exchanging and sharing information via Web documents with rich multimedia content. The WEBTOUR is a system implementing the idea to record and replay dynamic multimedia annotations on Web documents in the form of guided Web tours (Sastry et al., 1999). The dynamic multimedia annotations in this system include mouse gestures, drawings, audio comments, video segments and hyperlink traversals. Therefore, lecturers can use WEBTOUR to capture instructional activities on HTML formatted course materials as well as he/she was teaching on a board.

\subsection{Writing Environment for Language Learning}

Writing is usually an obstacle for non-native users when they are learning a foreign language. With the advances of Internet, many Web sites are especially designed for English learning, providing various teaching materials for self-studies. The Purdue OWL (Online Writing Lab) is a good site to support students in raising their English writing. They provide writing consultative services with two common communication ways: by face-to-face tutoring and by e-mails. Students could send their articles by e-mail to the OWL center and then wait for the response about writing problems or be notified to discuss with a consultant face to face in a physical office.

Traditionally, an instructor usually corrects a composition directly in printed draft. With the research achievements in the field of Computer-Aided Language Learning (CALL), instructors can correct compositions by the assistance of computers. The literature (Farkas \& Poltrock, 1995) summarized three common methods for computer-based correcting tasks:

(1) Modifying the draft directly: Editors received digital drafts, and used the text editor to revise the draft directly. In this method, authors and editors must trust each other because the revised points can not be recovered easily, and it is difficult for authors to know which content part is revised.

(2) Adding notes and free style symbols into text: Editors give comments in margins or draw symbols to indicate the revisions. This method keeps the overall reflection of the editors that could be viewed by the author, including the organization of the composition or the style of writing. However, using free style symbols to edit is a laborious way when editing a large number of drafts.

(3) Using clear and concise symbols for correcting: Editors use a virtual red pen to draw understandable symbols on digital draft. This method is similar to the traditional paperbased editing by using a red pen, and it helps to revise drafts efficiently.

According to the discussion above, the feasible editing model is to adopt traditional paperbased markings that are familiar and intuitive for editors and authors to the computer screen. MATE is one of the marking-based systems developed for collaborating writing with digital ink (Hardock et al., 1993). The system uses mark recognition to support automatically incorporating changes into the document. The document data structure using in the system contains information about relationships between the annotations and text of the document. The authors mentioned about the importance of speech for editing tasks, but they regarded 
the feature as the future work. The CoCoA system adopts the similar concepts developed to support correcting work between instructors and students (Ogata et al., 1997). The system designed several visualized markings to correct the article by using computers for Japanese composition studies. Both systems described above, however, only support the presentation in static text, markings, or comments. Few multimedia features are involved to enhance the editing task. According to the investigation of Schar (Schar \& Krueger, 2000), the voice can have a structuring effect and attract the user's attention to important elements in the picture.

\section{An Overview of WMA System}

The purpose of the Web-based Multimedia Annotation (WMA) system is to assist learners in English composition studies. The system proposed a comprehensive solution for simulating face-to-face writing tutoring to help non-native users improve their writing skill by several pre-designed proofreading markings or free-form pen strokes. For example, Figure 1 illustrates the editing result consisting of instructor's narration and several navigation events which include proofreading markings or free-form pen strokes. The pre-designed proofreading markings and their corresponding operations are shown in Table 1.

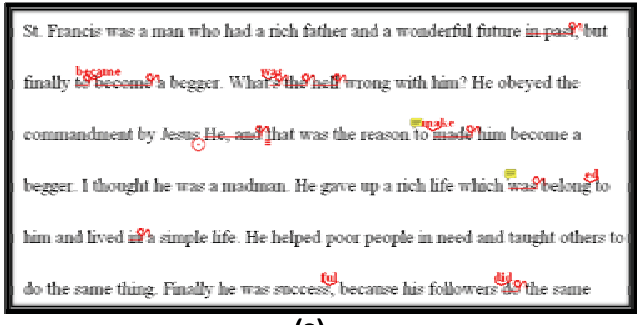

(a)

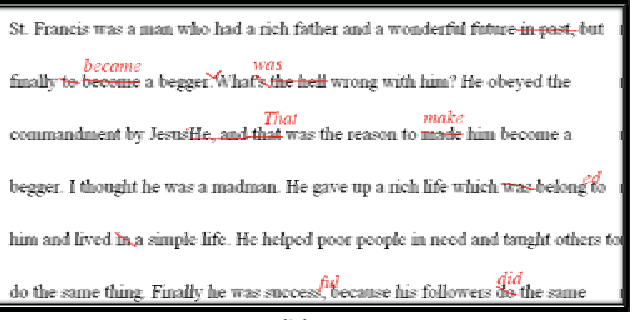

(b)

Fig. 1. The composition is corrected by (a) proofreading markings or (b) free-form pen strokes and annotations

\begin{tabular}{|c|c|c|c|}
\hline \multicolumn{4}{|c|}{ *Note: Using "space" key to switch the correcting mode (pen or marking mode) } \\
\hline \multicolumn{2}{|c|}{ Marking } & Description & Operation \\
\hline \multirow{2}{*}{$\stackrel{0}{0}$} & Was- & Pen stroke & Pressing 'left button' of the mouse and dragging it \\
\hline & belong to & Annotation & Pressing key of ' $a$ ' to invoke annotation \\
\hline \multirow{4}{*}{ 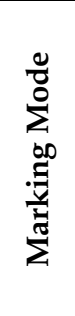 } & alos & Spelling check & $\begin{array}{l}\text { Using mouse to select the letters and pressing key } \\
\text { of ' } s \text { ' to invoke the marking }\end{array}$ \\
\hline & e्gypt & Capital letter & $\begin{array}{l}\text { Using mouse to select the letters and pressing key } \\
\text { of 'c' to invoke the marking }\end{array}$ \\
\hline & All & Lower case & $\begin{array}{l}\text { Using mouse to select the letters and pressing key } \\
\text { of ' } l \text { ' to invoke the marking }\end{array}$ \\
\hline & keeping & Take out & $\begin{array}{l}\text { Using mouse to select the letters and pressing key } \\
\text { of ' } d \text { ' to invoke the marking }\end{array}$ \\
\hline
\end{tabular}




\begin{tabular}{|l|l|l|l|}
\hline & $\begin{array}{r}\text { ful } \\
\text { success, }\end{array}$ & Insert & $\begin{array}{l}\text { Clicking mouse to identify the insertion point and } \\
\text { pressing key of ' } i \text { ' to invoke the marking }\end{array}$ \\
\hline \multirow{2}{*}{ Byes } & Punctuation & $\begin{array}{l}\text { Clicking mouse to identify the insertion point and } \\
\text { pressing punctuation keys }\end{array}$ \\
\hline s $\begin{array}{l}\text { Selecting the letters to be deleted and pressing key } \\
\text { of ' } i \text { ' to invoke the marking }\end{array}$ & Replace & $\begin{array}{l}\text { Selecting the letters and use the mouse to drag } \\
\text { them to the target, a sub-menu will be popped up }\end{array}$ \\
\hline go to & Transpose & $\begin{array}{l}\text { Selecting the letters and use the mouse to drag } \\
\text { them to the target, a sub-menu will be popped up }\end{array}$ \\
\hline go to & Bracket move & $\begin{array}{l}\text { Selecting the letters and use the mouse to drag } \\
\text { them to the target, a sub-menu will be popped up }\end{array}$ \\
\hline comment & Comment & $\begin{array}{l}\text { Clicking mouse to identify the insertion point and } \\
\text { pressing key of ' } a \text { ' to invoke the marking }\end{array}$ \\
\hline
\end{tabular}

Table 1. Full reference of operations for free-form pen strokes and proofreading markings

During the recording process, the instructor can use simple mouse operations combined with keyboard entry to trigger the drawing functions of different markings shown on the computer screen or switch operation functions between pen and marking modes arbitrarily. After the compositions are corrected, the learners can access editing results with audiovisual synchronized presentation via Internet or download the packaged files that could be played offline. In the presentation stage, the recorded navigation events will be displayed dynamically in accordance with synchronization information to enrich lecture presentation. Figure 2 shows an example which all of events (e.g., tele-pointer, highlight, marking-based annotations and scrolling) can be rendered synchronously along with the timestamps of playing speech.

In this example (Knoy, 2000), the original sentence is "A statistical comparison is made of the proposed procedures with Taguchi's two-step procedure." After the sentence is corrected by the instructor through recording tool, the visualized markings show that the sentence should be reorganized as "The proposed procedures and Taguchi's two-step procedure are statistically compared." We use several screen snapshots of key events to illustrate the presentation process. The scenario is detailed in the following: when a user requests a lecture, at $\mathrm{T} 1$, the browser with implemented synchronization mechanisms will be initialized by loading the HTML-format composition, corresponding speech and synchronization information. At T2, an event is triggered to correct the letter " $\mathrm{t}$ " by using a "capital letter" marking. The "replace" event, which is the combination of "take out" and "insert" markings, is invoked at T3. At T4, the punctuation is deleted by invoking a "take out" operation. At T5, a "replace" event is triggered again and an "insert" event follows it at T6. At T7 and T8, the "replace" and "take out" events are triggered, respectively. At T9, the "bracket move" marking is used to reorganize the sentence. Finally, the edited result will be shown on the display window at T10. The tele-pointer which is supplementary guidance will appear during the whole presentation process. 


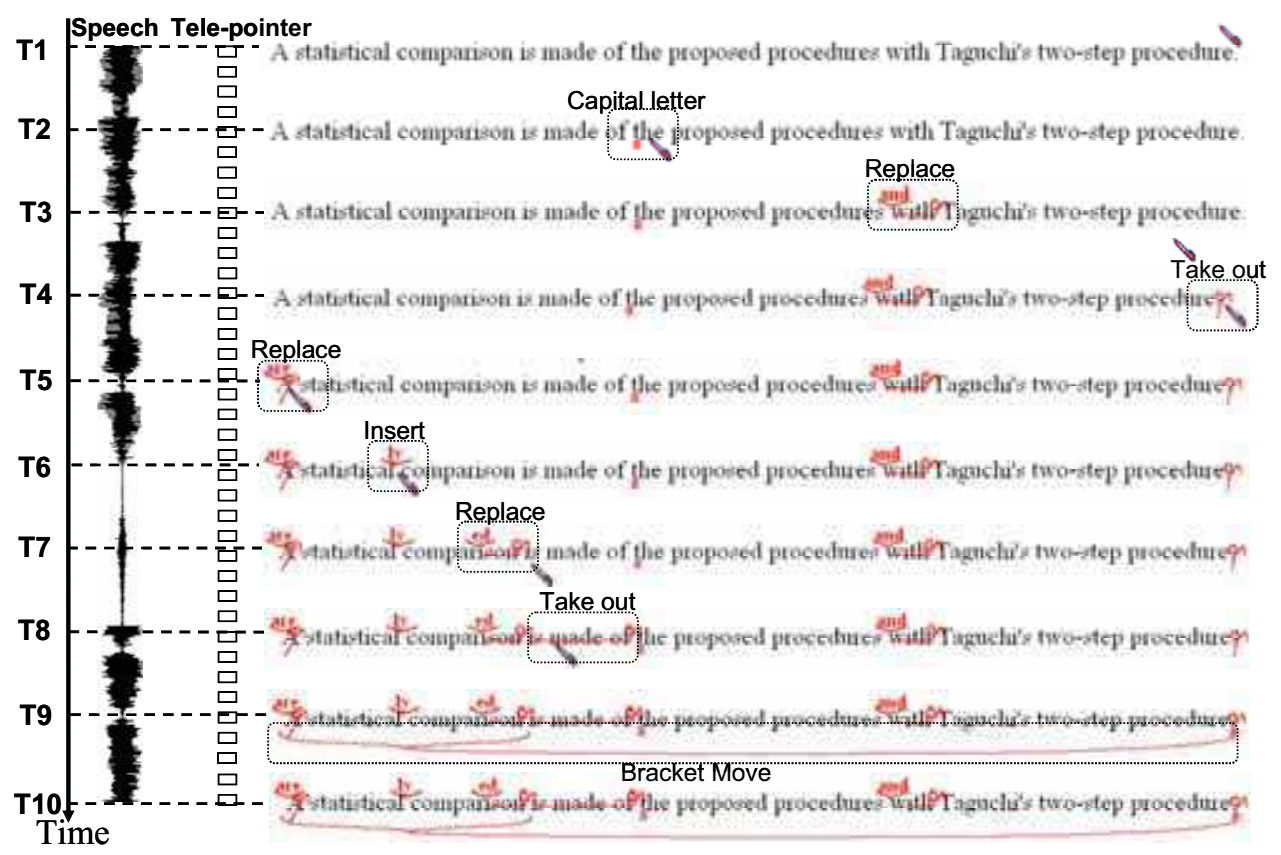

Fig. 2. An example of synchronized presentation with various marking-based annotations

\section{Recording Procedures}

In our developed WMA system, we provide two versions to record the lectures for instructors: online and offline. The former is constructed to apply to an environment with stable broadband network (e.g. on campus), and the latter is designed for instructors who are at somewhere with no network or unstable connections (e.g. at home). Additionally, both versions support one phase and three phases recording modes. In what follows, we will describe these features in detail.

\subsection{Online version}

Online learning is the most popular way for establishing a learning environment. Figure 3 shows the architecture of the online scenario in our system. We adopted the client/server architecture in common use to manage the learning resources. Learners can submit compositions through a submission interface, and the content will be stored on the Database. Once an instructor starts the Multimedia Lecture Recorder, the content of a composition will be loaded. The instructor can use the functions provided by our system to correct the compositions. After the instructor finished the recording, the voice and captured events will be uploaded to the WMA server automatically. For a learner, he/she can access the corrected compositions via the Multimedia Lecture Viewer. All of involved media objects will be downloaded, and the lecturing process could be restored faithfully according to the captured events in the recording stage. 


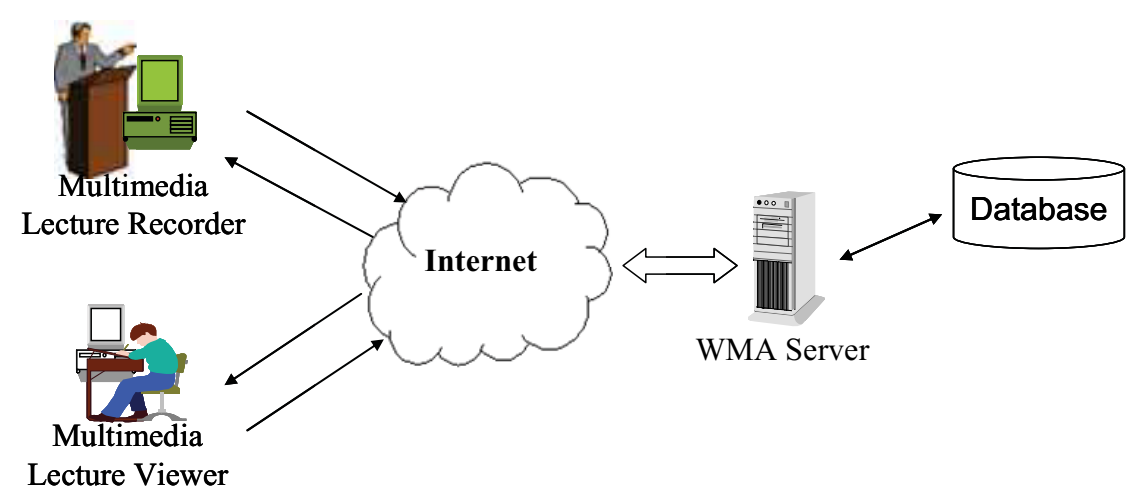

Fig. 3. Client/Server architecture for composition studies

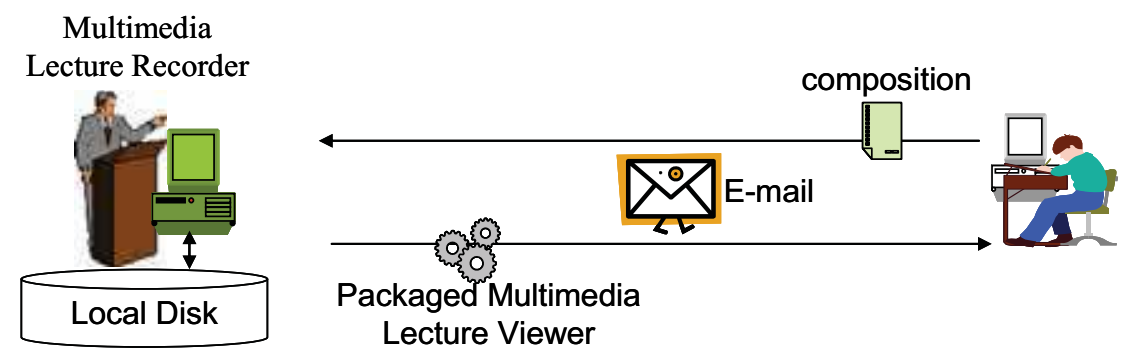

Fig. 4. Correcting procedures for offline version

\subsection{Offline version}

One reason for us to develop the offline version is the unstable of network connections. Although it is convenient to convey information through the Internet, sometimes instructors may encounter unexpected network problems that cause the miss or failure in uploading of captured materials. Another reason is that it is difficult for an instructor to prepare equipments for setting up the WMA server. Thus in the offline scenario, the related tools of WMA system are packaged as a stand-alone application for instructors to install on their local computers. Figure 4 shows the correcting procedures of the offline scenario. Resources exchange and transmit are achieved by the traditional e-mails. The communication steps are described as follows: (1) a learner prepares his/her composition in pure text (.txt) or MS Word (.doc) format, and then sends the file by attaching in a mail to the instructor. (2) After receiving the mail, the instructor can start the recording tool and import the content of composition into the recorder. (3) Once the instructor finishes the recording, all of involved media objects (including Multimedia Lecture Viewer) will be packaged into a zip file, and the instructor can send the packaged file to the learner. (4) The learner can extract the file and open the Multimedia Lecture Viewer to access the corrected composition as well as the online access.

Our system provides two scenarios for English composition studies. The former (online) is suitable for an organization which contains many affiliates, and the latter (offline) may be helpful for personal use in a class. 


\subsection{Recording modes}

Recording is usually a sequential task. Although our system provides functions of "pause" and "resume" to control the recording pace, it may still cause some instructors to record a lecture under pressure. The reason is that the instructor doesn't want to miss the errors required to correct, or to make mistakes when correcting. In our system, we devised an "undo" function for instructors to cancel the visualized events (e.g., markings, pen strokes or annotation) during the recording stage; however, the recording captures various data streams (text, navigation events and voice) in real-time, further analysis for "undo" operation is required. After a visualized event was canceled, the system needs to have the ability to remove the corresponding segment of other streams. This is the reason to explore media correlation in our system (Liu \& Chen, 2005). To cancel visualized events seems to be a good solution during the recording, but any automated analysis process couldn't ensure that its analyzed result is perfect. Therefore, "undo" is an optional function for instructors.

In order to redeem the insufficient of our capturing tool and to reduce the pressure on instructors, we make a little bit change on the recording procedure. Instructors can achieve the recording in accordance with the following steps:

(1) Revising content directly: Before the recording, the instructor can revise the content of student's composition directly as well as the operations in a text editor. Figure 5 is an example to edit the content of a composition.

St. Francis had a wonderful future in
past, but finally to become a beggar.

(a) Before editing
St. Francis had a wonderful future,

but finally becalme a beggar.

Fig. 5. An example of text editing, (a) before editing and (b) after editing

(2) Comparing the differences of content between revisions automatically: In our capturing tool, we applied the algorithm implemented by Neil (Neil, 2007) on the differences comparison between text contents. The differences, including additions, deletions will be highlighted in different colors, as shown in Figure 6(a). In this presentation mode, too much information is shown on the screen that may annoy the instructor during the correcting process. Thus our system will transfer the presentation from text-based to marking-based according to the compared result, as Figure 6(b) shows.

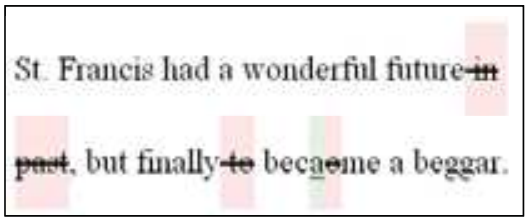

(a) Text-based

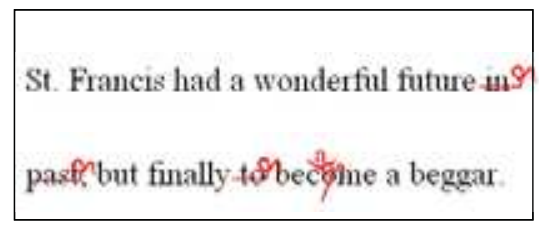

(b) Marking-based

Fig. 6. After the comparison between Figure 5(a) and Figure 5(b)

(3) Recording voice comments: After the comparison is achieved, the instructor can start to record voice comments according to the revised points. The operation functions listed in Table 1 still work in this phase. 


\begin{tabular}{|c|c|}
\hline \multirow{5}{*}{$\begin{array}{l}\text { St. Francis was a man who had a rich father } \\
\text { and a wonderful future, but finally_became } \\
\text { a begger. Whatwas wrong with him? He } \\
\text { obeyed the commandment by Jesus, That } \\
\text { was the reason to made him become a } \\
\text { begger. I thought he was a madman. He gave } \\
\text { up a rich life which belonged to him and }\end{array}$} & 舸除: in past \\
\hline & 甽除: to \\
\hline & 船除: 。 \\
\hline & 刑除: 's \\
\hline & Nof除: the hell \\
\hline $\begin{array}{l}\text { lived a simple life. He helped poor people in } \\
\text { need and taught others to do the same thing. }\end{array}$ & 那除: $\mathrm{He}$, \\
\hline Finally he was successful, because his & 甽除: and \\
\hline followers did the same thing like him and he & 形除: was \\
\hline has been respected at any time in any place & 畍除: in \\
\hline & 㓩除: do \\
\hline
\end{tabular}

Fig. 7. An example of corrected composition opened in the MS Word

\section{Presentation Modes}

Once a learner requests an online corrected lecture from the WMA server or opens an offline corrected lecture from the local computer, default presentation mode of the Multimedia Lecture Viewer is marking-based. All visualized events will be rendered on the screen, and once the learner presses the 'play' button, the correcting process can be reconstructed by synchronization mechanism. In addition to general random access function, we devised a process to analyze the relationships between speech data and the visualized events to facilitate the cross-media access (Liu \& Chen, 2005). The process is used to find out the speech segment of explanation related to a visualized event. Therefore, a learner can retrieve the corresponding explanation by clicking a visualized event.

Another presentation mode in our system is text-based. In this mode, a learner will still see the entire correcting process without markings. The correcting points will be presented as well as the actual task of editing by a text editor. Moreover, our system supports the exporting of corrected composition to an HTML document that is compatible with the MS Word. Thus the exported file could be opened by MS Word application, and all the correcting points will be shown by enabling the editing trace function. Figure 7 is an example of the exported file opened by the MS Word.

\section{Conclusion}

We have established an environment using multimedia features for English composition studies, and the system has been used on campus of Providence University (http://english.cs.pu.edu.tw) and National Chi Nan University (http://english.csie.ncnu.edu.tw). We hope that the system functions will be helpful for both instructors and students in their teaching and learning. 


\section{References}

Brotherton, J. (2001). Enriching Everday Activities through the Automated Capture and Access of Live Experiences, Ph.D. Thesis, Georgia Tech.

Brusilovsky, P. (2000). Web lectures: Electronic presentations in Web-based instruction, pp. 18-23, Syllabus $13(5)$

Cruz, G., and Hill, R. (1994). Capturing and Playing Multimedia Events with STREAMS, pp. 193-200, Proceedings of ACM Multimedia, San Francisco, CA, USA

Datta, A., and Ottmann, T. (2001). Towards a Virtual University, Journal of Universal Computer Science, Vol. 7, No. 10, 870-885

Farkas, D.K., and Poltrock, S.E. (1995). Online editing, mark-up models and the workplace lives of editors and writers, IEEE Transactions on Professional Communication, Vol. 38, No. 2, 110-117

Gellevij, M., van der Meij, H., Jong, T., and Pieters, J. (2002). Visuals in Instruction: Functions of Screen Captures in Software Manuals, pp. 1501-1511, Proceedings of the International Workshop on Dynamic Visualizations and Learning, Tubingen, Germany

Gleicher, M. L., Heck, R. M., and Wallick, M. N. (2002). A Framework for Virtual Videography, pp. 9-16, Proceedings of the 2nd International Symposium on Smart Graphics, Hawthorne, New York, USA

Hardock, G., Kurtenbach, G., and Buxton, W. (1993). A marking based interface for collaborative writing, pp. 259-266, Proceedings of the 6th annual ACM symposium on User interface software and technology, Atlanta, Georgia

Knoy, T. An Editing Workbook for Chinese Technical Writers, 2000.

Latchman, H. A., and Gillet, D. (2000). A New Approach in the Use of Multimedia for Technology Enhanced Learning, pp. 3449-3453, Proceedings of the American Control Conference, Chicago, Illinois, USA

Lauer, T., Muller, R., and Ottmann, T. (2001). Animations for Teaching Purposes: Now and Tomorrow, Journal of Universal Computer Science, Vol. 7, No. 5, 420-433

Liu, K. Y. and Chen, H. Y. (2005). Exploring Media Correlation and Synchronization for Navigated Hypermedia Documents, pp. 61-70, Proceedings of the 13th ACM International Conference on Multimedia, Singapore

Mukhopadhyay, S., and Smith, B. (1999). Passive Capture and Structuring of Lectures, pp. 477-487, Proceedings of the 7th ACM International Conference on Multimedia, Orlando, Florida, USA

Muller, R. and Ottmann, T. (2000). The "Authoring on the Fly" system for Automated Recording and Replay of (tele)presentations, Journal of Multimedia Systems, Vol. 8, No. 3, 158-176

Neil, F. (2007). The Implementation and Extension of the Diff Algorithm proposed by Paul Heckel. See: http://neil.fraser.name/writing/diff/.

Ogata, H., Yano, Y., and Wakita, R. (1997). COCOA: A Communicative Correction Assisting System for Composition Studies, pp. 461-468, Proceedings of International Conference on Computers in Education, Sarawak, Malaysia

Rowe, L. A., Harley, D., and Pletcher, P. (2001). BIBS: A Lecture Webcasting System. Technical Report, Berkeley Multimedia Research Center, U.C. Berkeley.

Rui, Y., Gupta, A., Grudin J., and He, L. (2004). Automating Lecture Capture and Broadcast: Technology and Videography, Journal of Multimedia Systems, Vol. 10, No. 1, 3-15 
Sastry, C. R., Lewis D. P., and Pizano, A. (1999). WEBTOUR: A System to Record and Playback Dynamic Multimedia Annotations on Web Document Content, pp. 175178, Proceedings of the 7th ACM International Conference on Multimedia, Orlando, Florida, USA

Schar, S.G., and Krueger, H. (2000). Using New Learning Technologies with Multimedia, IEEE Multimedia, Vol. 7, No. 3, 40-51

Schillings, V., and Meinel, C. (2002). tele-TASK - Teleteaching Anywhere Solution Kit, pp. 130-133, Proceedings of the 30th annual ACM SIGUCCS Conference on User Services, Providence, Rhode Island, USA

Shi, Y., Xie, W., Xu, G., Shi, R., Chen, E., Mao, Y., and Liu, F. (2003). The Smart Classroom: Merging Technologies for Seamless Tele-Education, Journal of IEEE Pervasive Computing, Vol. 2, No. 2, 47-55

Steinmetz, R. (1996). Human Perception of Jitter and Media Synchronization, Journal of IEEE Selected Areas in Communications, Vol. 14, No. 1, 61-72

Suganuma, A. (2002). Development of an Automatic Camera Control System for Videoing a Normal Classroom to Realize a Distant Lecture, pp. 1892-1897, Proceedings of ELearn 2002, Montreal, Canada

Wang, F., Ngo, C. W., and Pong, T. C. (2003). Synchronization of Lecture Videos and Electronic Slides by Video Text Analysis, pp. 315-318, Proceedings of the 11th ACM International Conference on Multimedia, Berkeley, California 


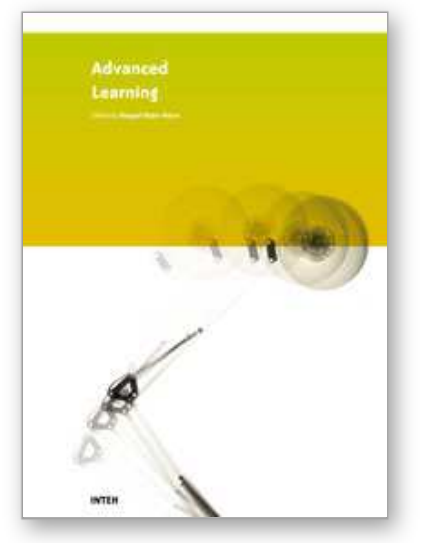

\author{
Advanced Learning \\ Edited by Raquel Hijn-Neira
}

ISBN 978-953-307-010-0

Hard cover, 444 pages

Publisher InTech

Published online 01, October, 2009

Published in print edition October, 2009

The education industry has obviously been influenced by the Internet revolution. Teaching and learning methods have changed significantly since the coming of the Web and it is very likely they will keep evolving many years to come thanks to it. A good example of this changing reality is the spectacular development of eLearning. In a more particular way, the Web 2.0 has offered to the teaching industry a set of tools and practices that are modifying the learning systems and knowledge transmission methods. Teachers and students can use these tools in a variety of ways aimed to the general purpose of promoting collaborative work. The editor would like to thank the authors, who have committed so much effort to the publication of this work. She is sure that this volume will certainly be of great help for students, teachers and researchers. This was, at least, the main aim of the authors.

\title{
How to reference
}

In order to correctly reference this scholarly work, feel free to copy and paste the following:

Kuo-Yu Liu and Herng-Yow Chen (2009). A Web-based Multimedia Annotation System for Language Learning, Advanced Learning, Raquel Hijn-Neira (Ed.), ISBN: 978-953-307-010-0, InTech, Available from: http://www.intechopen.com/books/advanced-learning/a-web-based-multimedia-annotation-system-forlanguage-learning

\section{INTECH}

open science | open minds

\section{InTech Europe}

University Campus STeP Ri

Slavka Krautzeka 83/A

51000 Rijeka, Croatia

Phone: +385 (51) 770447

Fax: +385 (51) 686166

www.intechopen.com

\section{InTech China}

Unit 405, Office Block, Hotel Equatorial Shanghai

No.65, Yan An Road (West), Shanghai, 200040, China

中国上海市延安西路65号上海国际贵都大饭店办公楼 405 单元

Phone: +86-21-62489820

Fax: $+86-21-62489821$ 
(C) 2009 The Author(s). Licensee IntechOpen. This chapter is distributed under the terms of the Creative Commons Attribution-NonCommercial-ShareAlike-3.0 License, which permits use, distribution and reproduction for non-commercial purposes, provided the original is properly cited and derivative works building on this content are distributed under the same license. 